\title{
REUTILIZAÇÃO DE TUBOS DE PAPELÃO: estudo da impermeabilização visando sua aplicação no design de produtos
}

\author{
Mariana Piccoli \\ UFSM - Universidade Federal de Santa Maria \\ marianap.piccoli@gmail.com \\ Joyson Pacheco \\ UFRGS - Universidade Federal do Rio Grande do Sul \\ joyson@mecanica.ufrgs.br \\ [Luis Henrique Alves Cândido \\ UFRGS - Universidade Federal do Rio Grande do Sul \\ pslhc@ibest.com.br] \\ [Leonardo Barili Brandi \\ UFRGS - Universidade Federal do Rio Grande do Sul \\ leonardo.barili@gmail.com]
}

Resumo: A reutilização aumenta e valoriza o ciclo de vida dos produtos sem necessidade da desintegração do material, proporcionando um destino adequado e o aproveitamento da configuração formal, da energia e matéria-prima agregadas e das propriedades inerentes ao produto que é descartado. Este trabalho teve como objetivo identificar parâmetros técnicos de absorção, recobrimentos e impermeabilização, visando possibilitar a reutilização de tubos de papelão, provenientes de descarte, no desenvolvimento de produtos. Para a realização dos ensaios técnicos, efetuou-se a coleta dos tubos até ser atingida a quantidade necessária, aferiram-se suas medidas e confeccionaram-se os corpos de prova. Em seguida foram realizados ensaios técnicos de absorção de água e testes de recobrimento. Como resultado, no teste de absorção de água, constatou-se que os tubos são higroscópicos, necessitando de impermeabilização; para reconhecer um material de recobrimento adequado para os tubos de papelão, refez-se o ensaio de absorção de água com os tubos revestidos por tintas e vernizes à base de água. O melhor resultado foi apresentado pelo verniz marítimo em três demãos, revestimento que foi analisado por microscopia eletrônica de varredura. Por fim, acredita-se que o estudo e reconhecimento de características peculiares de novos materiais é um ponto determinante para a inserção destes no Design.

Palavras-chave: reutilização, tubos de papelão, parâmetros técnicos, design, impermeabilização. 


\begin{abstract}
The reuse increases and enhances the life cycle of the product without the disintegration of the material, providing a correct destination and use of formal configuration, energy and raw material and aggregate properties inherent to the product or material that is discarded. This study aims to identify the technical parameters of absorption, coatings and waterproofing to reuse cardboard tubes, from disposal in product development. For conducting technical trials, performed the collection tubes until reach the required amount, have assessed up your measurements and sewed up the specimens. Then, technical tests of water absorption and coating testing were performed. As a result, in the water absorption test, it was found that the tubes are hygroscopic, requiring waterproofing; to recognize a material suitable for coating cardboard tubes, the water absorption test is remade and tubes were coated with paints and varnishes water-based. The best result was presented by three coats of marine varnish, coating was analyzed by MEV. Finally, it's believed that the recognition and study of specific characteristics of new materials is a key factor on its insertion in product design.
\end{abstract}

Key-words: reuse, cardboard tubes, technical parameters, product design, waterproofing.

\title{
1. INTRODUÇÃO
}

O design está presente em tudo que nos cerca - ele nos segue da manhã à noite, em casa, no trabalho, no lazer, no transporte, na saúde. A vida da maioria das pessoas é inimaginável sem a presença do design, pois como assevera Bürdek (2006), é por meio dos produtos que nos comunicamos com outras pessoas, nos definimos em grupos sociais e marcamos nossa situação social. Porém, conforme afirma Papanek (1995), o poder do design pode influenciar a vida das pessoas e o meio ambiente para o bem ou para o mal.

Sendo o design é o agente de tudo que nos cerca e a atividade projetual relacionada à criação dos elementos e estruturas físicas voltadas ao ser humano, seria ele também o responsável pelo problema enfrentado com o manejo e descarte de todos os produtos? Afinal, tudo que é produzido - desde uma caneta, uma embalagem ou até um automóvel - será descartado em algum momento.

Um dos possíveis caminhos para a redução ou eliminação dos resíduos sólidos é a aplicação do conceito dos 3RS (reduzir, reutilizar e reciclar), que visa a melhoria das condições ambientais e uma relação mais harmônica entre o ambiente natural e o consumidor. Para Barbero e Cozzo (2009), os conceitos de reciclagem e reutilização, apesar de similares, diferenciam-se pela natureza dos produtos a que dão origem: na reciclagem prevê-se a transformação e reutilização do material (ou materiais) daquilo que é reciclado, e na reutilização volta-se a dar uso ao próprio objeto. No primeiro caso, são os materiais que perduram no tempo para além da duração do produto; e no segundo, é o próprio produto.

Dentre os resíduos sólidos gerados pela indústria de papel e celulose (4⿳亠口冋 maior produtora de resíduos no Rio Grande do Sul, de acordo com FEPAM, 2013, p. 13) e 
com grande potencial de uso, está o tubo de papelão, objeto de estudo deste trabalho. Caracterizado como resíduo industrial não perigoso, os tubos de papelão são utilizados em diversos segmentos industriais - seja na forma de embalagem ou como suporte para o enrolamento de tecido, papéis, borrachas, adesivos e outros tipos de películas.

Segundo Preston e Bank (2012, p. 657) os tubos de papel são produtos de alto nível de engenharia estrutural, usados principalmente nas indústrias de papel e tecidos. Também são utilizados como formas para construção de pilares de concreto.

O objetivo geral deste trabalho é identificar parâmetros técnicos de absorção, recobrimentos e impermeabilização visando criar conhecimentos para possibilitar a reutilização de tubos de papelão, provenientes de descarte, no desenvolvimento de produtos. Como confirmam Petutschnigg e Ebner (2007, p. 408), a aplicação de novos materiais é dependente principalmente das suas propriedades específicas, incentivando a análise e estudo destas características.

A metodologia de trabalho é baseada em pesquisa bibliográfica sobre materiais de impermeabilização, e realização de ensaios técnicos para a definição dos melhores materiais de recobrimento. Para a realização dos ensaios técnicos, efetuou-se a coleta dos tubos até ser atingida a quantidade necessária, aferiram-se suas medidas e confeccionaram-se os corpos de prova. Em seguida foram realizados ensaios técnicos de absorção de água e testes de recobrimento através da imersão dos corpos de prova em um recipiente com água, e posterior pesagem em momentos pré-estabelecidos.

\section{DESENVOLVIMENTO}

Este trabalho está focado no estudo de materiais de recobrimento (tintas e vernizes), que correspondam aos critérios de ecodesign, e que possam evitar a absorção de umidade pelos tubos de papelão.

Os materiais naturais - e os derivados deles, como é o caso do tubo de papelão - possuem uma série de vantagens típicas, dentre elas: serem renováveis, leves e recicláveis. Por outro lado, possuem aspectos que podem ser considerados desvantagens, como sua fácil decomposição. Assim, apesar do seu intrínseco caráter ecológico, podem tornar-se ambientalmente prejudiciais se coloridos ou impregnados com substâncias tóxicas para evitar a decomposição (LJUNGBERG, 2007, p. 472).

As definições de Fazenda (2005) sobre os componentes básicos das tintas são:

- Resina: parte não volátil da tinta, que aglomera as partículas de pigmentos.

- Pigmento: material sólido finamente dividido, utilizado para conferir cor, opacidade e características de resistência.

- Aditivo: afere características especiais ou melhora as propriedades das tintas.

- Solvente: líquido volátil utilizado para dissolver a resina.

Segundo Manzini e Vezzoli (2002, p. 155) as tintas são problemas, devido às potenciais emissões de Compostos Orgânicos Voláteis (COV), que podem ser reduzidas utilizando tintas vegetais ou à base de água. Para os autores, nos acabamentos em madeiras (material citado como exemplo que mais se assemelha ao tubo de papelão), é melhor evitar as pinturas e solventes à base de derivados do petróleo (tem altas emissões de (OV), sendo aconselhados as tintas e vernizes a base de água e os vernizes vulcanizados a ultravioleta.

Para Fazenda et al. (2005, p. 5-6), a necessidade de proteger o meio ambiente é um fator importante no desenvolvimento tecnológico das tintas; tem-se alcançado 
grandes progressos, permitindo diminuir a emissão de solventes orgânicos na aplicação e cura das tintas. Por exemplo: a substituição dos sistemas à base de solventes orgânicos por sistemas aquosos; desenvolvimento de tintas em pó e de cura por radiação e redução ou eliminação de produtos tóxicos na composição das tintas.

As resinas à base de água são muito parecidas com as à base de solventes, mas não é uma substituição simples de solventes orgânicos por água. Exigiu pesquisa e desenvolvimento em aditivos e técnicas de fabricação para que as tintas pudessem conter menos solventes (FAZENDA, 2005). As vantagens dessas tintas são várias: menor exposição do pintor aos efeitos do solvente, menor risco de explosões e incêndio e diminuição da contaminação ambiental.

Na Figura 1 pode-se comparar a composição de alguns tipos de tintas em termos da porcentagem presente de solventes, resina, pigmentos e água. Observa-se a baixa porcentagem de solventes (cerca de $2 \%$ ) nas tintas à base de água, enquanto que nas tintas convencionais este valor chega a $70 \%$.
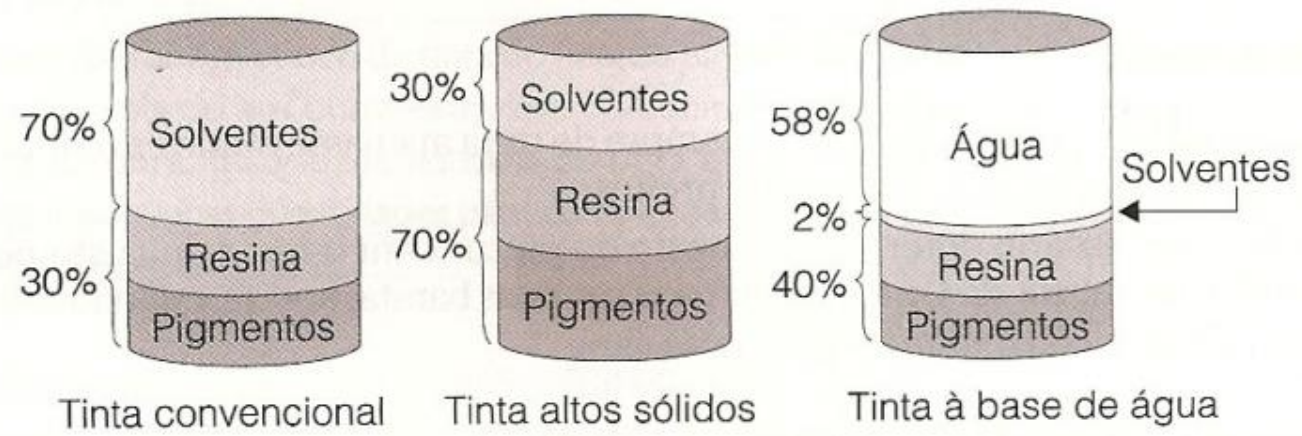

Tinta à base de água

Figura 1 - Composição de alguns tipos de tintas.

Fonte: Fazenda (2005, p. 748).

Nennewitz et al. (2008, p. 156) apresentam os perigos do uso de solventes e diluentes orgânicos, como álcoois, éteres e hidrocarbonetos. O benzeno, por exemplo, é nocivo à saúde, cancerígeno e passível de explosão; tolueno, xileno e estireno podem provocar inconsciência e alterações na formação do sangue; etanol e álcool são passíveis de explosão, nocivos à saúde, podem ser absorvidos pela pele, danificam o sistema nervoso, o fígado e os rins. Em contraponto, a água é amigável ao meio ambiente e não nociva à saúde.

A preocupação em evitar a absorção da água pelos tubos de papelão também aparece no trabalho de Preston e Bank (2012), que investigaram diferentes métodos de impermeabilização. Segundo os autores, os raios ultravioletas do sol são uma das possíveis formas de causar danos, mas o principal é manter os tubos secos, já que eles são muito sensíveis às mudanças do teor de umidade, perdendo sua resistência.

\subsection{Materiais e métodos}

Os tubos de papelão utilizados neste estudo são resíduos do processo de impressão gráfica, fornecidos pela empresa Signs Up Comunicação Visual, localizada em Porto Alegre. Suas medidas são: diâmetro interno $76,2 \mathrm{~mm}$ e espessura da borda $5 \mathrm{~mm}$. O processo de coleta foi realizado até atingir-se uma quantidade de material suficiente para a realização dos ensaios. 
A fim de guiar o procedimento de confecção dos corpos de prova, utilizou-se a ABNT NBR 14101:1998 - Papel e cartão - Tubetes - Amostragem para ensaios, que determina as seguintes definições:

- Espécime: tubete completo, não danificado, retirado de um lote.

- Amostra: conjunto de todos os espécimes.

- Corpo de prova: tubete completo ou uma seção de um tubete sobre o qual o ensaio é executado de acordo com o método de ensaio normalizado.

Durante todo o período anterior aos ensaios, os tubos foram protegidos das influências que pudessem alterar suas propriedades, como a luz direta do sol, flutuações climáticas consideráveis, líquidos e umidade, conforme dita a norma.

Ressalta-se que, de todos os espécimes coletados, foram descartados $100 \mathrm{~mm}$ de cada uma das extremidades, em conformidade com a norma ABNT NBR 14257:1998 Papel e cartão - Tubetes - Determinação da umidade - Método por secagem em estufa.

Somente depois de estabelecido o equilíbrio de umidade entre os corpos de prova e atmosfera (requerido para estabilizar o estado físico dos materiais) é que os materiais foram submetidos aos ensaios. Para isso, foram mantidos por um período entre sete e dez dias na atmosfera condicionadora de temperatura $23^{\circ} \mathrm{C}$ e umidade relativa 50\%, conforme ABNT NBR 14102:2002 Papel e cartão - Tubetes Condicionamento das amostras, até que atingissem a massa constante.

Os corpos de prova foram cortados rigorosamente a $90^{\circ}$ com relação ao seu eixo em uma serra circular de esquadria modelo LS1040, da Makita ${ }^{\circledR}$; potência de $1650 \mathrm{~W}$ e 4600 rpm, equipada com disco de corte com lâmina de wídea de 32 dentes, sem causar deformações, e suas medidas foram aferidas com o uso de trena e paquímetro universal. A retirada das rebarbas da superfície cortada foi obtida pelo uso de lixas. Identificaram-se todos os corpos de prova com um marcador a prova d'água.

As etapas do ensaio envolveram: secagem dos corpos de prova em estufa à temperatura de $105^{\circ} \mathrm{C}$ até atingirem massa constante; pesagem dos CPs em uma balança digital de precisão após o tempo de secagem; recobrimento com os materiais definidos, e novamente pesagem após esta etapa; imersão dos mesmos em um recipiente com $6 \mathrm{l}$ de água à temperatura ambiente e posterior pesagem em períodos de tempo pré-determinados.

A estufa utilizada é da marca De Leo, com controlador de temperatura de $50^{\circ} \mathrm{C}$ a $250^{\circ} \mathrm{C}$, e a balança digital é da marca Quimis ${ }^{\circledR}$, com capacidade total de $210 \mathrm{~g}$ e resolução de 0,1mg, ambos equipamentos pertencentes ao Laboratório de Design e Seleção de Materiais (LdSM - UFRGS).

Foram avaliados alguns materiais para recobrimentos no tubo de papelão, a fim de reconhecer aquele que se adeque ao objetivo de reduzir a absorção de água. Após ensaios preliminares e estudo sobre impermeabilizantes para madeira e papel, definiram-se como recobrimentos a serem experimentados os seguintes:

- Resina acrílica impermeabilizante multiuso à base de água: Pode ser aplicada em interiores e exteriores, em vários tipos de materiais. Composta por resina acrílica emulsionável, dióxido de titânio, espessantes, pigmentos orgânicos e inorgânicos, dispersantes e conservantes.

- Termolina leitosa: verniz para impermeabilizar tecido, isopor, papel e outros materiais. Composta por copolímero vinílico, água e conservante. 
- Tinta acrílica à base de água: composta por resina acrílica modificada, pigmentos ativos e inertes, aditivos e água.

- Tinta esmalte à base de água: indicado para proteger superfícies externas e internas de madeira, metais ferrosos, galvanizados, alumínio e PVC. Composta por resina acrílica modificada, pigmentos ativos e inertes, aditivos e água.

- Verniz acrílico à base de água: indicado para dar acabamento em madeira, papel, cortiça, cerâmica, gesso, metal e isopor. Composto por resina de emulsão acrílica, água e conservantes.

- Verniz marítimo à base de água: verniz especialmente desenvolvido para uso interno e externo em superfícies de madeira. Produto à base de copolímeros acrílicos em emulsão, bactericida e fungicida não metálico, aditivos e água.

As informações sobre cada material foram obtidas diretamente em suas embalagens. A definição destes revestimentos deu-se pelos seguintes motivos: utilização de água como base da resina, estudo de materiais impermeabilizantes e facilidade de compra em estabelecimentos comerciais (nos segmentos de artesanato ou construção civil). Ressalta-se a utilização apenas de materiais sem substâncias tóxicas e metais pesados e solúveis em água, respeitando as diretrizes de ecodesign.

Todos os materiais são nacionais, e foram seguidas as recomendações de utilização dos fabricantes dos materiais aplicados - temperatura ideal e métodos de aplicação, tempo de espera entre demãos. Ensaiaram-se sessenta e cinco corpos de prova; 10 para cada material de revestimento (sendo cinco com duas demãos e os outros cinco com três demãos) e mais cinco corpos de prova sem revestimento.

Esperou-se os corpos de prova atingirem o estado de equilíbrio de umidade e massa constante previamente ao recobrimento, na atmosfera condicionadora de temperatura $23 \pm 1^{\circ} \mathrm{C}$ e umidade relativa $50 \pm 2 \%$, conforme ABNT NBR 14102:2002 Papel e cartão - Tubetes-Condicionamento das amostras.

\subsection{Realização dos ensaios técnicos}

O recobrimento foi realizado com pincel de cerdas suaves, da marca Atlas, com largura de $25 \mathrm{~mm}$, ideal para pintura com vernizes (Figura 2), em uma capela de pintura localizada no LdSM. Segundo Nennewitz et al. (2008, p. 146), o processo de revestimento com pincel tem um grau de eficiência de aplicação de $98 \%$, enquanto que a eficiência do método de pintura por imersão pode variar de 80 a 98\%, não sendo indicado para peças com cavidades.

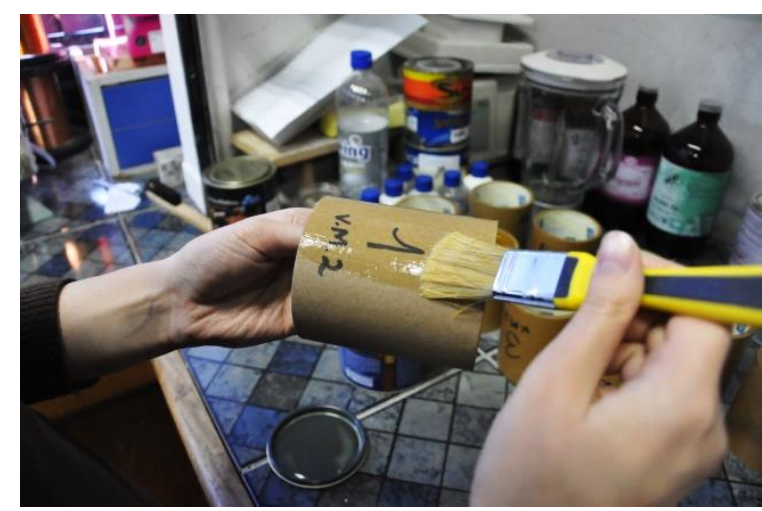

Figura 2 - Verniz sendo aplicado no tubo de papelão com o auxílio de um pincel de cerdas macias. Fonte: elaborado pelo autor, com base na pesquisa realizada. 
Os recobrimentos foram aplicados em duas e três demãos (cinco corpos de prova para cada grupo), na superfície interna, externa e nas bordas superiores e inferiores dos tubos, após eles terem atingido o equilíbrio de umidade na atmosfera condicionadora de temperatura $23 \pm 1^{\circ} \mathrm{C}$ e umidade relativa $50 \pm 2 \%$, conforme $A B N T$ NBR 14102:2002 Papel e cartão - Tubetes-Condicionamento das amostras.

A temperatura no local e dia da aplicação era $20 \pm 3^{\circ} \mathrm{C}$, e a umidade relativa $60 \%$. Após a aplicação, os corpos de prova foram mantidos novamente na atmosfera controlada anteriormente citada $\left(23 \pm 1^{\circ} \mathrm{C}\right.$ e $50 \pm 2 \%$ de umidade relativa) por três dias, para secagem e cura total dos materiais de revestimento.

Após o tempo total de cura e secagem em ambiente climatizado (sete dias), os corpos de prova foram imersos em um recipiente com 61 de água e pesados em determinados momentos (novamente $10 \mathrm{~s}, 30 \mathrm{~s}, 1 \mathrm{~min}, 5 \mathrm{~min}, 10 \mathrm{~min}$ e $20 \mathrm{~min}$ ).

A seguir podem-se ver os corpos de prova com três demãos de cada revestimento (Figura 3). As cores da tinta esmalte (marrom escuro) e acrílica (cinza) foram definidas pelo fato de serem as já adquiridas pela autora do trabalho.

Em relação ao aspecto visual dos corpos de prova com cada recobrimento, fazem-se as seguintes observações: o verniz marítimo (Figura $3 \mathrm{~A}$ ) resultou em um acabamento brilhante e com coloração amarelada, escurecendo os tubos de papelão; o verniz acrílico (Figura 3B) alterou sutilmente a cor, dando um acabamento acetinado; as tintas, tanto a esmalte (Figura $3 \mathrm{C}$ ) quanto a acrílica (Figura 3D), resultaram em um acabamento semi-brilhante, ocultando completamente o material; a termolina (Figura 3E) foi o recobrimento considerado mais discreto, dando um leve brilho sem alteração da cor dos tubos; já a resina multiuso (Figura 3F) resultou em um acabamento muito brilhante, mas sem alterar a cor original dos materiais.
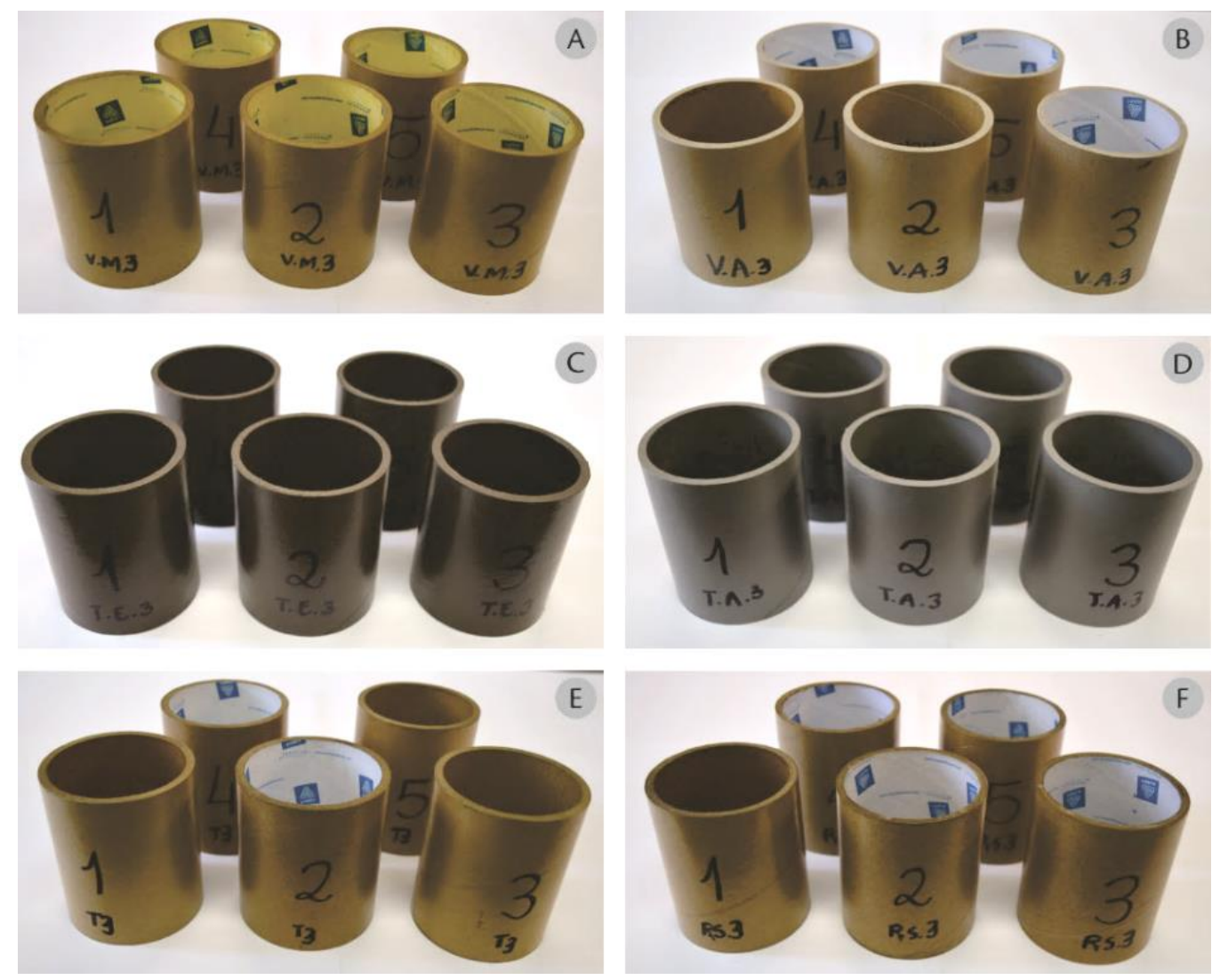
Figura 3 - (A) Corpos de prova revestidos com verniz marítimo; (B) Vermiz acrílico; (C) Tinta esmalte; (D) Tinta acrílica; (E) Termolina e (F) Resina multiuso. Todos os materiais de recobrimento são à base de água.

Fonte: elaborado pelo autor, com base na pesquisa realizada.

O aumento de espessura foi imperceptível a olho nu; segundo alguns fabricantes, a aplicação de três camadas de tinta, com pincel, causa um aumento de cerca de $70 \mu \mathrm{m}$ na espessura. Abaixo, podem-se ver os corpos de prova sem revestimento (Figura 4), que seguiram o procedimento do ensaio juntamente com os corpos de prova recobertos.

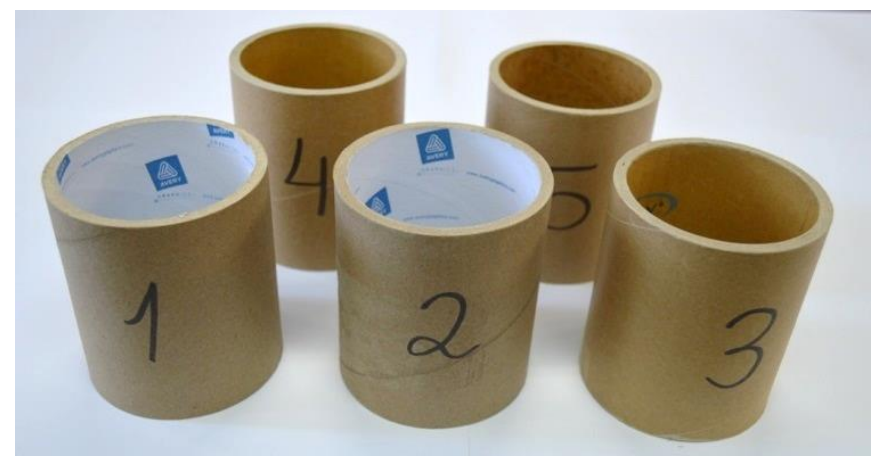

Figura 4 - Corpos de prova sem revestimento.

Fonte: elaborado pelo autor, com base na pesquisa realizada.

Uma amostra coberta com o material que obteve o melhor resultado no ensaio de absorção foi analisada no microscópio eletrônico de varredura, localizado no LdSM, para identificar de que forma o revestimento proporcionou a impermeabilização.

\section{CONCLUSÃO}

Os resultados apresentados por todos os recobrimentos foram unidos em um gráfico (Figura 5), com a média de todos os valores, que permite comparar a porcentagem de absorção em relação ao tempo, tendo como valor inicial (100\%) a massa após o recobrimento - no caso dos CPs sem recobrimento, 100\% refere-se à massa em equilíbrio de umidade.

Pela visualização do gráfico, pode-se concluir que o melhor resultado de impermeabilização foi apresentado pelo verniz marítimo aplicado em 3 demãos, seguido da tinta esmalte aplicada em 3 demãos, o verniz marítimo em 2 demãos e o verniz acrílico aplicado em 3 demãos, também considerados resultados satisfatórios. 


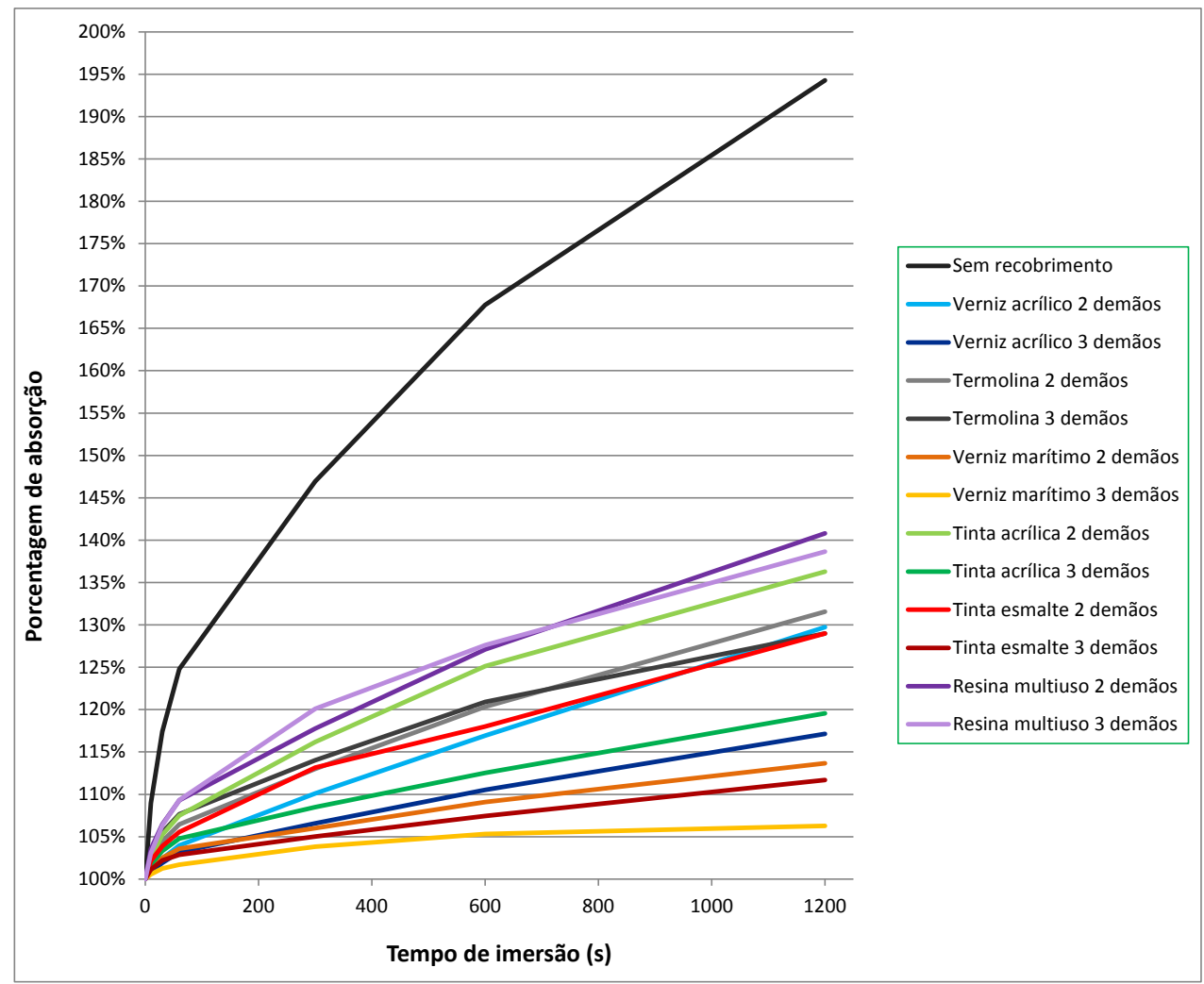

Figura 5 - Resultados dos ensaios de absorção dos diferentes recobrimentos testados.

Fonte: elaborado pelo autor, com base na pesquisa realizada.

O aspecto visual e tátil dos corpos de prova após os ensaios (Figura 6) corrobora com os dados do gráfico: os tubos sem recobrimento (Figura 6A) apresentaram manchas de infiltração, aumento da espessura da borda e camadas internas descolando; aqueles recobertos com verniz acrílico (Figura 6B) tiveram infiltração principalmente na porção próxima às bordas dos tubos, e percebeu-se um aumento na espessura; os revestidos com termolina (Figura 6C) tiveram algumas infiltrações localizadas, e pequenas rachaduras; os corpos de prova revestidos com verniz marítimo (Figura 6D) apresentaram poucas manchas de infiltração e não demonstraram fragilidade ou amolecimento; aqueles recobertos com tinta acrílica (Figura 6E) e esmalte (Figura 6F) tiveram enrugamentos e inchamento nas áreas próximas às bordas; os recobertos com a resina multiuso (Figura 6G) estavam amolecidos, inchados, com manchas de infiltração, com as camadas soltando-se e com rachaduras em vários pontos (detalhe na Figura $6 \mathrm{H}$ ). 

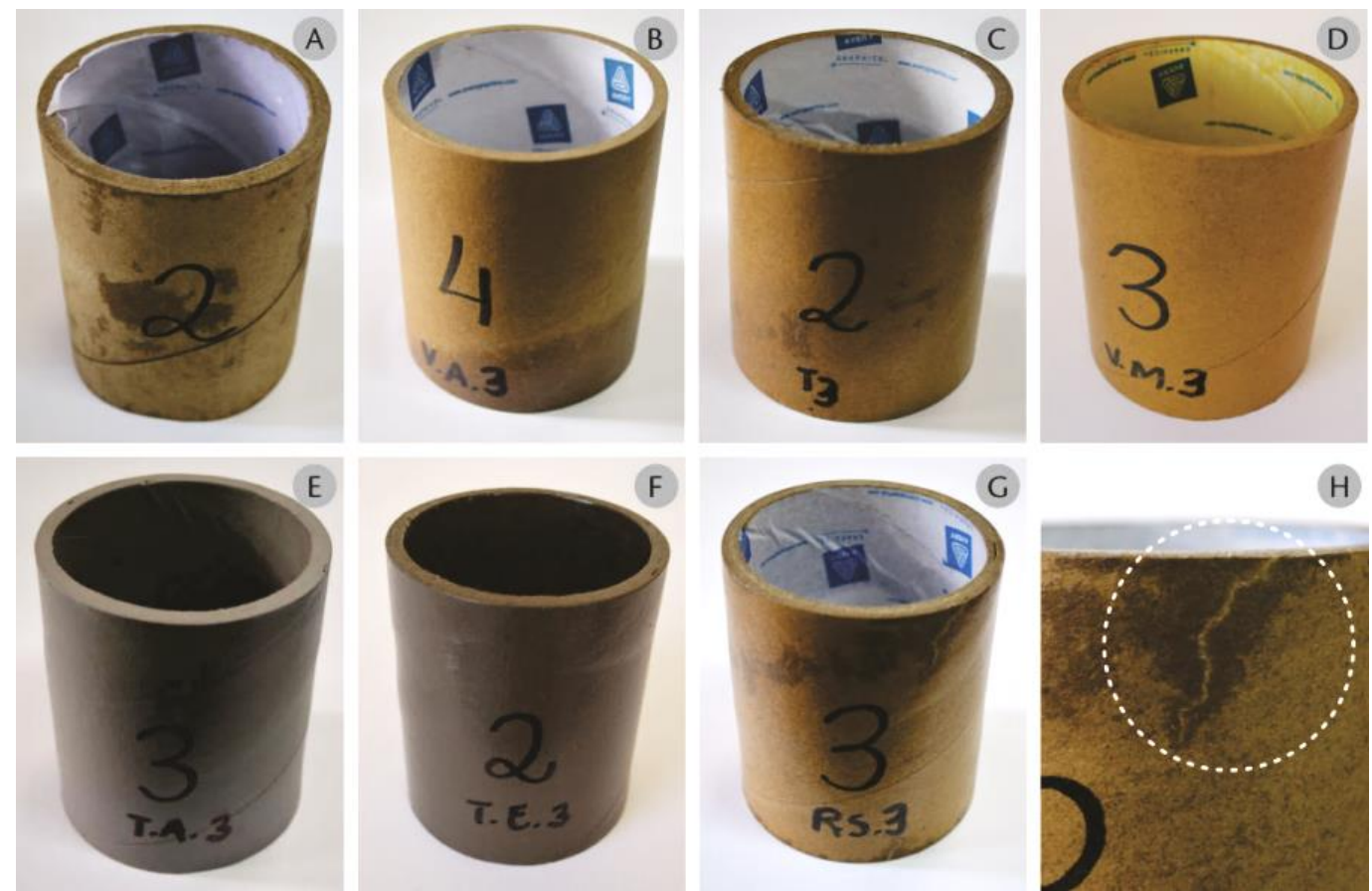

Figura 6 - Aspecto visual dos corpos de prova após o ensaio de absorção. (A) Sem revestimento; (B) Revestimento verniz acrílico, 3 demãos; (C) Revestimento termolina, 3 demãos; (D) Revestimento verniz marítimo, 3 demãos; (E) Revestimento tinta acrílica, 3 demãos; (F) Revestimento tinta esmalte, 3 demãos; (G) Revestimento resina multiuso, 3 demãos; (H) Detalhe da infilitração e rachaduras com o revestimento resina multiuso 3 demãos.

Fonte: elaborado pelo autor, com base na pesquisa realizada.

De forma a identificar de que forma o verniz marítimo gerou uma impermeabilização tão satisfatória, recortou-se uma amostra de $10 \mathrm{~mm} \times 10 \mathrm{~mm}$ do corpo de prova número um, revestido com três demãos de verniz marítimo, para analisá-la por microscopia eletrônica de varredura (Figura 7).
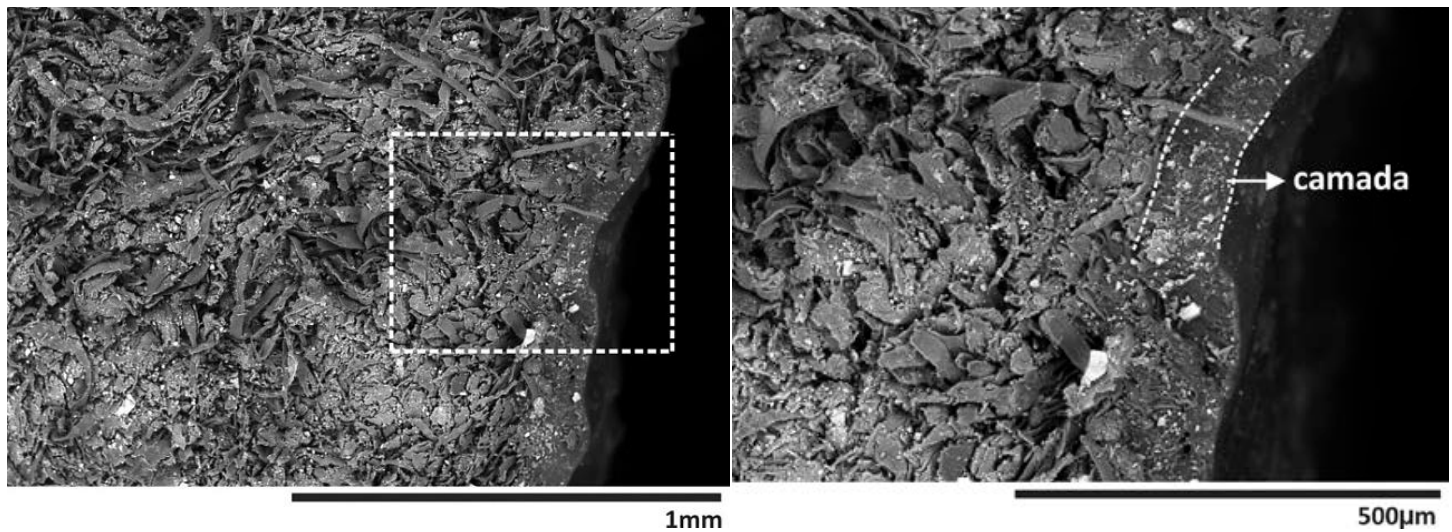

Figura 1 - Microscopia eletrônica de varredura do tubo de papelão revestido com três demãos de verniz marítimo. À esquerda: borda sem revestimento, onde se pode visualizar a camada criada pelo verniz marítimo; à direita: ampliação da área quadriculada na imagem anterior, destacando a referida camada.

Fonte: elaborado pelo autor, com base na pesquisa realizada.

Pela microscopia realizada na borda recortada, sem revestimento, pode-se visualizar a camada criada pelo verniz marítimo; a área destacada com o quadriculado 
é ampliada, onde se evidencia a espessura da referida camada, reconhecida em cerca de $80 \mu \mathrm{m}$.

Após a comprovação de que os tubos de papelão são um material higroscópico, com um aumento de aproximadamente 50\% na massa dos corpos de prova submetidos a 10 minutos de imersão em água, reconheceu-se que o melhor material à base de água para seu recobrimento e impermeabilização é o verniz marítimo aplicado em três demãos. Os corpos de prova revestidos com este material tiveram um aumento de massa de apenas $6 \%$ após 20 minutos de imersão, e criou-se uma barreira protetora de $80 \mu \mathrm{m}$ de espessura, reconhecida através de microscopia eletrônica de varredura.

Porém, o recobrimento com verniz marítimo deixou um aspecto amarelado; caso a intenção seja não alterar visualmente a aparência dos tubos de papelão, devese realizar o recobrimento com verniz acrílico em três demãos, cujo resultado de $17,15 \%$ de aumento na massa dos corpos de prova após os 20 minutos de imersão também foi considerado satisfatório.

Apesar de se ter considerado o resultado de impermeabilização suficiente, os tubos não tem características para aplicações em produtos para áreas externas que fiquem expostos a intempéries como chuva, vento e sol direto. Não foi realizado o ensaio de absorção em tubos que já haviam sido imersos, e depois secos; podem ocorrer rachaduras que facilitam a penetração de água mesmo após uma primeira imersão bem sucedida.

O estudo e reconhecimento de características peculiares de novos materiais é um ponto determinante para a inserção destes no design. Aspectos culturais relegam o papelão a uma função secundária, como embalagem, por exemplo, e não como matéria prima na fabricação de produtos. Mas essa concepção está mudando, na medida em que encontram referências, se projetam produtos e, principalmente, se descobrem as características deste material.

Considera-se que os objetivos propostos por esta pesquisa foram atingidos; porém, para se validar os parâmetros identificados, seria importante a aplicação do material no desenvolvimento de produtos.

Como sugestão para trabalhos futuros, está refazer o ensaio de recobrimento, testando a aplicação dos materiais impermeabilizantes somente na borda dos tubos região considerada mais sensível à penetração de água, pois o papel da superfície externa é mais nobre, e nas bordas as fibras ficam expostas. Além disso, a absorção de umidade e as alterações provocadas nos tubos de papelão pelas condições climáticas poderiam ser avaliadas de forma mais detalhada através do uso de uma câmara climática, reconhecendo se há ou não a viabilidade de utilização dos tubos de papelão em áreas externas.

\section{REFERÊNCIAS}

ASSOCIAÇÃO BRASILEIRA DE NORMAS TÉCNICAS. NBR 14101: papel e cartão: tubetes: amostragem para ensaios. Rio de Janeiro, 1998.

ASSOCIAÇÃO BRASILEIRA DE NORMAS TÉCNICAS. NBR 14257: papel e cartão: tubetes: determinação da umidade: método por secagem em estufa. Rio de Janeiro, 1998.

BÜRDEK, Bernhard. História, teoria e prática do design de produtos. São Paulo: Edgard Blücher, 2006. 
FAZENDA, Jorge M. R (coord.). Tintas e vernizes: ciência e tecnologia. São Paulo: Edgard Blücher, 2005.

FEPAM. Biblioteca Digital. Disponível em: <http://www.fepam.rs.gov.br/biblioteca/rsi.asp>. Acesso em: jul. 2012.

LUNGBERG, Lennart. Materials selection and design for development of sustainable products. In: Materials and Design, n 28, 2007, p. 466-479.

MANZINI, Ezio; VEZZOLI, Carlo. O desenvolvimento de produtos sustentáveis: os requisitos ambientais dos produtos industriais. São Paulo: EDUSP, 2002.

NENNEWITZ, Ingo; NUTSCH, Wolgang; PESCHEL, Peter; SEIFERT, Gerhard. Manual de tecnologia da madeira. São Paulo: Edgard Blücher, 2008.

PAPANEK, Victor. Arquitetura e design: ecologia e ética. Lisboa: Edições 70, 1995.

PETUTSCHNIGG, Alexander Johannes; EBNER, Michael. Lightweight paper materials for furniture - a design study to develop and evaluate materials and joints. In: Materials \& Design, n 28, 2007, p. 408-413.

PRESTON, Steven J.; BANK, Lawrence C. Portals to an Architecture: Design of a temporary structure with paper tubes. In: Construction and Building Materials, n 30, 2012, p. 657-666. 